\title{
Research on Information Disclosure of Internal Control in Asia-Pacific Industrial Company
}

\author{
Yinling Liu \\ School of Management, Yulin University, China,719000 \\ 263050607@qq.com
}

Keywords: Asia-pacific industrial company; Internal control; Information disclosure; Audit

\begin{abstract}
With the continuous development of social economy, the information disclosure of internal control is related to the enterprise of vital importance. However, from the current situation of listed companies, there are still many problems in the internal control information disclosure of the listed company's internal control system construction is not perfect enough. Therefore, in this environment, it is necessary to speed up the research on internal control information disclosure, the stable development of enterprises play a key role. The Asia Pacific industry as an example, to the hand from the current situation of internal control information disclosure from 2014 to 2016 the Asia Pacific industry, found that the Asia Pacific industrial control information disclosure issues internally, and to propose relevant solutions. From the two aspects of internal and external supervision departments, and strive to improve the weak link of internal control information disclosure of Asia Pacific industry, so as to improve the survival and development of enterprises Power.
\end{abstract}

\section{Introduction}

With the rapid development of economy and the increasing competitiveness of listed companies, internal control of Listed Companies in China are faced with many challenges, enterprises frequent occurrence of major illegal events, from the early CAOSC Singapore company to map out "management override" problem, to green land laws and regulations for the issue of fraud case is ignored, then to the Department of financial fraud happened Edmond, have something to do with the construction of internal control has a great loss of [1]. Therefore, the internal control information of listed companies has been of concern to the community. In order to improve the construction of internal control system of Listed Companies in China, maintain the order of socialist market economy, the Ministry of Finance in conjunction with the relevant departments jointly issued the basic norms of "enterprise internal control", hope to improve the internal control information disclosure quality of listed companies, encourage enterprises to better health development.

\section{Analysis on Present Situation of Internal Control Information Disclosure of Asia - Pacific Industry Listed Companies}

Brief introduction to Asia Pacific Industrial Company. Asia Pacific Industrial Corporation was founded in February 12th 1988, with a registered capital of 323.27 million yuan. Lanzhou Asia Pacific Industry and Trade Group Co., Ltd. was successfully held in April 2009 by a listed enterprise. In February 8th 2010, the company was officially renamed as Asia Pacific Industry. The company has a wide range of business, involving many fields. Is a business tourism development, high-tech development, daily goods, textile sales, building materials, tourism crafts agent purchase and marketing, agricultural services, technical services and other diversified state-owned holding companies. However, in recent years, the company has continuously violated the disclosure of internal control information, so selecting the company as the research object is to discover the problems existing in the disclosure of internal control information, which will serve as a warning for other enterprises. 


\section{Comparison of the scope of information disclosure of internal control}

Table 1 Vertical comparison table of information disclosure of internal control

\begin{tabular}{|c|c|}
\hline period & \multicolumn{1}{c|}{ Scope of disclosure } \\
\hline 2014 & Internal control self-evaluation report \\
\hline 2015 & Internal control self-evaluation report, Audit report of internal control \\
\hline \multirow{2}{*}{2016} & Internal control self-evaluation report \\
\cline { 2 - 2 } & \multicolumn{1}{|c|}{ Audit report of internal control } \\
\cline { 2 - 2 } & $\begin{array}{l}\text { Independent Director and Board of Supervisors ' Independent Opinion on Internal } \\
\text { Control Self - evaluation Report }\end{array}$ \\
\hline
\end{tabular}

It can be seen from Table 1 that the Asia - Pacific real industry has disclosed an internal control self - evaluation report for 2014 - 2016. However, in 2014 and 2015, independent director and board of supervisors have not disclosed independent opinions on the internal control self - evaluation report, which is one of them. The Asia - Pacific real industry has not disclosed the internal control audit reports in 2014. However, in 2014 and 2016, the enterprise should disclose the internal control audit report, which is not consistent with the self - evaluation report opinions of the Board of Directors and the Board of Supervisors, and the internal control information disclosure is insufficient.

Comparison of Five Element Information Disclosure of Internal Control

Table 2 Disclosure of the five elements

\begin{tabular}{|c|c|c|c|c|}
\hline \multicolumn{2}{|c|}{ time } & 2014 & 2015 & 2016 \\
\hline \multirow{3}{*}{ Content of the five elements } & $\begin{array}{c}\text { Clear delegation of authority } \\
\text { and assignment of } \\
\text { responsibilities }\end{array}$ & yes & yes & yes \\
\cline { 2 - 5 } & $\begin{array}{c}\text { Establishment of the Board } \\
\text { of auditors }\end{array}$ & yes & yes & yes \\
\cline { 2 - 5 } & HR Policy & no & no & no \\
\cline { 2 - 5 } & Corporate culture and values & no & yes & yes \\
\hline risk assessment & & no & no & no \\
\hline Control Activities & & no & no & no \\
\hline $\begin{array}{c}\text { Information and } \\
\text { Communication }\end{array}$ & & yes & yes & yes \\
\hline internal supervision & & yes \\
\hline
\end{tabular}

As can be seen from table 2, the Asia Pacific Industrial for the five elements of the disclosure is not sufficient. Risk assessment in the internal environment of human resources policy, did not disclose the control activities for three years. In the risk assessment, the company did not disclose the risks and corresponding countermeasures, to give people feel like any potential risks that will make people feel empty. In the control of active disclosure is mention. In the aspect of information and communication, 2014 has not been disclosed. In the internal supervision, although the disclosure, but simply mention the company set up the board of directors, supervisors and the audit committee, carry out their duties, but in fact in the internal supervision exists a lot of problems. Although the company set up the audit committee, but did not give the corresponding staff, useless.

Comparative analysis of self - evaluation report and disclosure internal control self evaluation report. The company listed on the main board, in accordance with the provisions of guidelines for assessment of enterprise internal control, self evaluation of the effectiveness of the [2] response to the internal control of enterprise, the disclosure of the annual self evaluation report 
"released by the corporate board of directors. The internal control report, is to evaluate the quality of information disclosure of internal control in the most critical and most important report [3].

First of all, from the point of view of the report format, in 2014, the report contains these parts: important statements, the company's internal control system overview, the company's key control activities, the promotion of the company's internal control construction. Overall evaluation; In 2015 and 2016, the disclosure is consistent, which are important statements, internal control evaluation conclusions, internal control evaluation work, internal control evaluation work basis and internal control defect identification standards. Identification and rectification of internal control defects and other major internal control related matters[4]. On 2014, the identification and rectification of internal control defects were added.

Secondly, from the point of view of disclosure, in 2014, the company mainly disclosed the internal control of the organizational structure of the company, the headquarters of the company has not set up a special audit institutions, the company's key control activities and other content. No further disclosure of any other material content, no disclosure of the most important five elements and internal control deficiencies; In 2015, on the basis of the 2014 disclosure, five elements of internal oversight and corporate culture in the internal environment were added, but only briefly described. It does not explain the company's cultural construction has any specific substantive measures. The non-financial reporting defects were simply disclosed; In 2016, on the basis of 2015 disclosure, the internal information transmission was added, but only a simple description of the company established the internal control information transmission related management system. There is no specific information transmission how to implement and what are the shortcomings.

From the analysis of three years' report disclosure, the disclosure format is not fixed, the content is not comprehensive, and the disclosure of the five elements of internal control and internal control defects is too little. Not enough.

\section{The problems of information disclosure in the internal control of Asia Pacific industry}

From the above analysis, it can be seen that the Asia - Pacific real industry has a lot of problems on the issue of internal control information disclosure. The Asia - Pacific real industry only attaches great importance to these issues in order to allow the company to develop for a long time. These problems can be broadly reflected in the following aspects:

Inconsistent reporting format. Whether China's main board listed companies can reasonably improve the internal control and implementation has gradually become the focus of attention of regulators and investors, but due to the lack of a corresponding standard for writing internal control evaluation report format. This leads to confusion in the form of internal control reports, which is even more difficult for users to refine relevant information. From the internal control self-evaluation report disclosure format. Asia Pacific Industrial from 2014 to 2016 report disclosure format is not fixed.

Disclosures are incomplete and inadequate. In the announcement of the internal control assessment, the Asia - Pacific real industry only disclosed the internal control self - evaluation report in 2014 . It is clear that the disclosure of the internal control audit report is not fully disclosed in 2015 and 2016, and it is difficult to believe the authenticity of the report. From the comparative analysis of the five - element disclosure analysis, it is clear that in 2014 , the Asia - Pacific real industry does not disclose the disclosure of the five elements, and the disclosure of the defect is not sufficient in 2014. In whole, whether the disclosure scope, the five elements, and the internal control self - evaluation report can be disclosed in the whole, are quite incomplete and insufficient .

The disclosure of internal control information is not valued, and the form is greater than substance. Asia Pacific industry nearly 3 years of "internal control self assessment report" in the content format is not improved, and the three years of the disclosure of internal control deficiencies exist many repeat, which indicates that the disclosure of internal control information form, and did not take specific measures to rectification, leading to the existence of the company internal control system problem. The information disclosure of internal control information needs not only to get more information, but also can make the company timely find the weak link of the internal control 
and rectification[2], but apparently did not understand the significance of Asia Pacific industry, internal control information disclosure disclosure forms in essence do things carelessly, and to improve the company's internal control system doesn't help.

Inadequate disclosure of internal control information. Generally, when there are significant defects in the internal control of the company, the opinions of the registered accountant to the internal control of the company shall be negative, and the corresponding internal control evaluation report of the company shall also issue a negative opinion. If the audit opinion is inconsistent with the conclusion of the internal control evaluation of the company, it shall indicate that the internal control evaluation work of the listed company is not rigorous, and also reflects the lack of emphasis on the internal control evaluation work within the company. First of all, the results of the internal control self - evaluation reports issued by the Asia - Pacific real industry in 2016 are inconsistent with the results of the internal control audit reports issued by the CPA. The Internal Control Self Evaluation Report of the Board of Directors considers that there is a significant deficiency in the internal control of the financial reporting period. However, in spite of the lack of strict compliance with that standard, the Asia - Pacific real industry does not classify the internal control defects strictly according to their own will, indicating that the Asia - Pacific real industry is not enough to disclose the internal control information .

\section{Optimization Countermeasures of Information Disclosure of Internal Control in Asia Pacific Industry}

Unified internal control information disclosure content and format. The disclosure of internal control information and the internal control self-evaluation report of listed companies need to establish a unified standard and format. At the same time, the specific format and content scope of the internal control evaluation report should be specified in detail. [7. First, the company should have formal documents or rules governing the content and format of disclosure of information from internal controls; Secondly, the opinions of CPA should be correct to show the evaluation and judgment of the company in the internal control, and the listed company should strictly follow the audit opinion of the CPA. Finally, the external regulatory authorities should strengthen supervision. The listed companies that do not disclose internal control information in accordance with the provisions should be punished according to the seriousness of the circumstances, and for the continuous illegal disclosure. If a warning or fine is given if the circumstances are serious, he shall be allowed to withdraw from the market.

Increased attention to internal control information disclosure. For a long time, most of the listed companies have a negative impact on the disclosure of internal control reports. It is believed that the disclosure will only increase the disclosure cost. If the flaws of internal control are disclosed, it will lead to the negative impact of the company . Therefore, this contradictory mindset makes many internal control imperfect companies dare not disclose internal control weaknesses , and fear the bad influence of external information demanders, which in turn affects the company ' $\mathrm{s}$ credit and financing. Therefore, the supervisory departments should guide the listed companies to attach importance to the disclosure of internal control information and promote the continuous strengthening of their own management and management.

Increase regulatory and audit efforts. The difference between the internal control self-evaluation report issued by Asia-Pacific Industry and the internal control audit report issued by CPA is due to the fact that the board of directors is not strict in issuing the report. Not responsible. The company should reasonably set up internal audit institutions and staff, regularly conduct professional ethics education to them, improve their moral cultivation. Before the report is issued. The company's internal audit department reviews the legal compliance of the report, including whether the division of internal control defects is standardized [9]. For governments, there is a need for greater oversight of standards for deficiencies in internal controls, so that they can be classified more rigorously [10].In order to avoid the similar problems in the future, the internal control information disclosure should be strictly checked from the internal and external supervision departments. 


\section{Conclusion}

The disclosure of high - quality internal control information is beneficial to the objective and timely understanding of the problems existing in the company, and further improves in time. The reason is that the management does not pay attention to the disclosure of internal control information, the external supervision and the related system are incomplete, and there is a lack of auditors in the company. Therefore, the internal and external regulators of the company should improve the relevant regulations, improve the supervision of the audit department, improve the degree of attention, and further improve the disclosure quality .

\section{References}

[1] Q.Wu. Study on Internal Control Problem and Countermeasure of " North Great Shortage " (MS., Capital University of Economics and Business, China 2014),P.3-5.

[2] J.Q.Sun. Research on Information Disclosure of Internal Control of listed companies in Agricultural and sideline products processing Industry in China(MS., Shandong University of Finance and Economics, China 2015)P.18.

[3] G.W.Jia,L.J.Zhu: Cooperative Economy and Science and Technology, Vol. 29 (2014) No.23, p.156-158.

[4] X.H.Zhang: Accounting Learning, Vol. 21 (2017) No.11, p.256.

[5] Y.Zhang: Shanxi Finance and Tax ,Vol. 37 (2016) No.9, p.32-34.

[6] Z.X.Meng. Analysis on the current situation of Information Disclosure of Internal Control of listed companies in China (MS., Southwestern University of Finance and Economics, China 2011) P.22.

[7] Y.J.Wang: Science \& Technology Vision, Vol. 6 (2016) No.18, p.275-276.

[8] Z.X.Meng: Reform of Economic System, Vol. 30 (2012) No.5, p.106-110.

[9] H.Q.Qi. An Empirical Study on the Effect of High - tube Characteristics on Internal Control Quality (MS., Shanxi Finance and Economics University, China 2011) P.25.

[10]W.J.Chen,X.J.Chen: Review of Corporate Governance, Vol. 3 (2011) No.01, p.36. 